\title{
Lurking towards empowerment: Explaining propensity to engage with online health support groups and its association with positive outcomes
}

Chris Fullwood $^{1^{\star}}$, Darren Chadwick ${ }^{1}$, Melanie Keep ${ }^{2}$, Alison Attrill-Smith ${ }^{1}$, Titus Asbury $^{3} \&$ Grainne Kirwan ${ }^{4}$

${ }^{1}$ Institute of Psychology, University of Wolverhampton, UK.

${ }^{2}$ Faculty of Health Sciences, University of Sydney, Australia

${ }^{3}$ Department of Psychology and Philosophy, Texas Woman's University, USA

${ }^{4}$ Department of Technology and Psychology, Institute of Art, Design and Technology, Ireland

*Corresponding author

Dr Chris Fullwood

Institute of Psychology, Faculty of Education, Health and Wellbeing, University of Wolverhampton, West Midlands, WV1 1LY, UK

E-mail: c.fullwood@wlv.ac.uk

Phone: +441902 323531

\section{Abstract}

Online health support groups (OHSGs) offer opportunities for people with various health conditions to gain support and associated physical and mental health benefits, however evidence suggests that those who choose to lurk in OHSGs may be less likely to accrue benefits (e.g. empowering outcomes) than those who actively contribute. Most research to date has focused on comparing the outcomes of OSHG engagement for lurkers and participators, yet there has been little research which has considered how the different reasons for lurking might be associated with levels of participation and empowering processes. In this investigation we used a survey to gather data from 237 participants to develop a new scale to measure factors influencing the Propensity for Online Community Contribution (POCCS), and to explore the relationship between these factors and OHSG engagement behaviour and empowering processes accrued from OHSG use. The POCCS comprised nine 
factors, 1) poor sense of community; 2) struggles with self-expression; 3) inhibited disclosure and privacy; 4) negative online interactions; 5) ease of access and use; 6) health preventing contribution; 7) delayed and selective contribution; 8) goals met without contribution; and 9) lack of time. Five of these factors $(1,3,6,7$, and 8) significantly predicted OHSG contribution and positive experiences in the form of empowering processes. Findings advocate a more nuanced approach to OHSG engagement, rather than a simple lurking/engaging dichotomy, and may enhance understanding of the relationship between OHSG use and perceived benefits.

Keywords: Online health support groups; lurking; empowerment; online contribution; online engagement

\section{Introduction}

Online health support groups (OHSGs) provide opportunities for people to access support, information and advice on a variety of different types of psychological and physical health conditions and to interact with other users who may have experienced similar life circumstances (Coulson \& Smedley, 2015). Seeking support online may be particularly advantageous to individuals who are living with rare, hidden, stigmatised or misunderstood health conditions, because finding others who can understand and appreciate what they are going through is likely to be much more challenging in the offline world (McKenna \& Bargh, 1998; Mickelson, 1997). Given that those who have access to more social support tend to show greater improvements in both physical and mental health (e.g. see Broadhead et al., 1983; Coker et al., 2002), removing barriers to providing effective support provision should be a primary concern for all online support communities. Using the Internet has 
shown great promise for supporting individuals living with various health conditions, particularly those who may have inadequate support networks available to them in their offline lives. However, we know that individuals interact with online support groups in distinctive ways and some individuals receive more benefits from those interactions than others. One activity which has been cited as potentially impeding the benefits accrued from online health support group participation is 'lurking', or the propensity for some users to spend more time observing the interactions of other online users, rather than making their own direct contributions to the community (Edelmann, 2013). However, little research has considered whether the different reasons for lurking in OHSGs might be related to the extent and types of contributions that people make as well as the kinds of benefits that might be accrued from engagement. The primary purpose of this study is to understand how the

different barriers to active participation in online health support groups (or the different reasons why some members might choose to lurk) interact with user engagement with these sites and the types and extent of benefits that they receive.

\section{Advantages of seeking support online}

Numerous advantages to seeking and receiving support in the online world over being supported offline have been reported. One of the most common ways in which supportive interactions take place via OHSGs is by using forums. Because forum interactions do not take place in real time, it is not necessary for members who are communicating with one another to be logged on to the site simultaneously. The asynchronous nature of online forums means that individuals seeking support can post messages and reply to other individuals when it is convenient for them to do so (Barak et al., 2008; Fullwood, 2016), which is particularly helpful to those whose 
illnesses or life circumstances may hinder their chances of regularly accessing online support. Moreover, the archived nature of forum interactions means that members can read the comments and replies that other users have left, benefitting from access to a diverse array of perspectives outside of the comments that have been specifically written for their attention (White \& Dorman, 2001; Fullwood, 2016).

Given that users have the option to choose how much personal information they disclose about themselves, many support seekers may elect to interact anonymously. Anonymous interactions can benefit those individuals who are more nervous or reluctant to share their personal stories in a face to face setting, in part because the level of risk associated with self-disclosure online is lessened (White \& Dorman, 2001). Users of OHSGs may also purposefully conceal certain physical or personal characteristics (e.g. their ethnicity or sex) if they are concerned that other community members may behave in a discriminatory fashion towards them (White \& Dorman, 2001). Online interactions via OHSGs can therefore be more egalitarian and provide a more level playing field for members (Fullwood, 2016).

Notwithstanding the potential to mask certain characteristics, online health support groups are generally very welcoming places where people with common ground meet to share experiences and offer emotional and practical support to one another (Eysenbach et al., 2004). One reason for this might be the sense of anonymity afforded by talking to strangers online. Interacting with unknown individuals online has been likened to the 'stranger on a train' phenomenon, whereby people feel more comfortable opening up about sensitive and personal topics (Whitty \& Joinson, 2008). It has also been suggested that by creating the conditions in which people 
feel freer to talk openly and honestly about the problems they are facing, more effective and personalised social support can be provided (Caplan \& Turner, 2007). Furthermore, encouraging users of OHSGs to provide support to others, in addition to seeking support for themselves, is likely to lead to more benefits as helping others can increase self-worth and create a sense of belonging and purpose (Taylor \& Turner, 2001). On this basis one might assume that in order to accrue the full extent of benefits associated with OHSGs, members need to engage in direct interactions with other users. However, there is evidence to suggest that the majority of individuals who access OHSGs prefer to passively consume information rather than actively contribute to the community (e.g. Mason, 1999; Nonnecke, 2000; Nonnecke \& Preece, 2000), despite the fact that many of the features of cyberspace should theoretically encourage greater self-disclosure.

\section{Lurking and the reasons why people lurk}

Lurking has been likened to bystander behaviour and is best understood as form of passive behaviour in which individuals will choose to observe rather than participate (Edelmann, 2013). Lurkers can make up a substantial proportion of any online community, with estimates ranging from $45.5 \%$ to $90 \%$ in some of the online communities which have been studied (e.g. see Mason, 1999; Nonnecke, 2000; Nonnecke \& Preece, 2000), however the specific type of support community (or 'topic') and community norms are also likely to play a large part in influencing how much people contribute. For example, Nonnecke and Preece (2001) noted that the lurking rate in a software support community was almost double that of a health support community, probably because many people log on to software support communities to get answers to generic problems, which will often have been 
answered by someone else. Also, personalised communication may be more likely to occur in a health support community where building bonds with other users may be more important.

There has been much debate in the academic literature about what it means to 'lurk'. Where some have argued that lurkers are those who do not create any new content for a site (e.g. Nonnecke \& Preece, 2003), others have proposed that lurking may entail at least a small level of contribution (e.g. Ridings et al., 2006). Defining 'lurking' is problematic because the behaviour of visitors to online communities may not be consistent across different sites. For example, Muller (2012) found that $84 \%$ of individuals who contributed to one or more online communities also lurked in at least one other community that they visited. There is also some debate around what period of time should elapse before a lack of contributions marks someone out as a lurker. Indeed, it is not uncommon for new members of sites to take some time to familiarise themselves with the community before they feel comfortable and confident enough to make a post (Malinen, 2015).

Lurking may perhaps be best conceptualised as existing on a continuum, rather than being a dichotomous variable. In other words, there are degrees of participation and various factors which might hinder individuals from making the level of contributions that they would like to make. Additionally, it should also be noted that lurkers do not always fail to contribute because they are inhibited from doing so. For example, it has been suggested that lurking might still be considered an active form of participation even though these individuals are not adding content to the site, because many lurkers will join groups in order to gratify a specific set of personal 
goals (Nonnecke et al., 2004). Some users may, for instance, not feel it necessary to post because they get what they need from the site from what others have contributed. Also, many contributors thrive on the knowledge that they have an audience. Even if people are registered but not contributing, their name may appear on the members list, and push up the 'audience' numbers. Nonetheless, one could also make the argument that in order for an OHSG to thrive, it requires at least some of its members to post content and reply to other users, and that greater numbers of contributions have the potential to benefit the community more widely as they will provide a more diverse array of perspectives and experiences (Fullwood, 2016). Although negative and pathological aspects which may be related to online lurking are possible (for example, spying, or depressive symptoms resulting from passive use of social media and negative social comparison; Lup, Trub, \& Rosenthal, 2015), here we are interested in the reasons for lurking only in online health contexts. We could find no evidence of negative behaviours of this nature pertaining to online health contexts. Indeed, recent research indicates that personality characteristics associated with negative online behaviours (e.g. Machiavellianism) are lower amongst lurkers (Seigfried-Spellar \& Lankford, 2018). This may suggest lurking is best distinguished from, rather than conflated with, negative online spying behaviour.

In trying to understand the different reasons why people lurk, Preece et al. (2004) canvased the opinions of 219 lurkers and highlighted five primary reasons why users do not contribute content to an online community. Some users may not contribute because they do not feel it necessary to post anything, for example because browsing others' content is sufficient to answer the questions that they have. Other users indicate that they do not post because they first need to find out more about 
the group. Some of these individuals may therefore be seen as 'potential' contributors, further supporting the argument that lurking does not have to be a fixed state (Malinen, 2015). Other users indicate problems with using the software, for example it might not be clear to them how they would go about making a post. Some users indicate not posting because they feel that they have nothing useful to add to the community, usually because they consider that other members have already said what they would like to say. Finally, some users express concerns about group dynamics, for example indicating that some of the other members are aggressive or rude, or that they had come to the realisation that the group was not the right fit for them. Not only is Preece et al.'s study interesting because it implies that lurkers are not always just 'free-riders' who take from the community without giving back, but it also suggests that there are a diverse set of reasons for why people do not make contributions. Understanding these potential reasons should provide impetus to maximise the user experience, not least through addressing limitations in the user interface or site design (Fullwood, 2016), but also in promoting their use to health groups and organisations.

More recently, Sun et al. (2014) developed a conceptual framework for helping to understand the different factors which might contribute to individuals choosing not to post to online communities. Within this framework, they first identified the key motivational factors driving online participation behaviour. They proposed that i) factors relating to the online community (e.g. its reputation, usability and group identity), ii) factors relating to level of commitment (e.g. the level of emotional attachment), iii) factors relating to the individual (e.g. their personal characteristics, goals and needs) and iv) factors relating to user's requirement for quality (e.g. how 
secure, reliable and convenient the site is) all influence online participation behaviour. In understanding the factors that drive online participation, they were then able to outline the primary reasons for why individuals might choose to lurk within online communities, namely: i) environmental reasons, ii) personal reasons, iii) relationship reasons and iv) security reasons.

Environmental reasons relate to elements of online communities which are outside of the individual's direct control, for example, whether the site is designed in such a way as to promote good quality interactions and the quality, timeliness and level of replies received from other members. Personal reasons might include aspects of the individual's personality. Introverts may prefer presenting themselves online because they have more control over their self-presentation (Valkenburg et al., 2005), but other personality traits (e.g. extraversion) may have a preference for the more 'personal' nature of face-to-face contact. Personal reasons could also relate to the specific personal needs that the individual has in relation to their support seeking behaviour as well as the individual's socio-economic circumstances. As previously noted, some individuals may only require information on their illness as opposed to emotional support in dealing with it (Preece et al., 2004; Fullwood, 2016). Further, one might refer here to Cutrona and Russell's (1990) 'optimal matching' hypothesis, which argues that individuals may require different types of support during different stages of their illness. There may be a stronger need for emotional support at the early stages of illness onset, partly because of the feelings of uncertainty, helplessness and lack of control that are created (Catrona \& Russell, 1990; Fullwood, 2016). In this sense, current 'lurkers' may have previously been more active participants in the past and may even become more active again in the future 
- lurking may thus be a transitory state and will depend greatly on the different life circumstances currently being experienced. Relationship reasons include the attitudes and dispositions that support-seekers hold towards specific communities. Those who feel a low level of commitment towards a group may feel less inclined to contribute content compared to individuals who have a stronger affiliation to the group. Finally, security reasons relate to issues around safety and privacy. For some users these may be a lack of trust in the security of the actual hardware and software that they are using, or they may feel disinclined to contribute because they are worried about oversharing, anonymity, confidentiality, or who might have access to the content that they post.

\section{Lurking and outcomes from OHSGs}

Although many individuals who lurk may still accrue positive benefits from visiting online health support groups (for example users may be inspired by the stories of others or find useful practical information relating to their illness) (Merry \& Simon 2012), research suggests that more active participants are likely to accrue more substantial benefits from OHSGs. Comparing the experiences of lurkers and nonlurkers in support groups for people living with AIDS/HIV for example, Mo and Coulson (2010) were interested in whether participation levels influenced any empowering outcomes associated with visiting these sites. In the study, lurkers were classified as individuals who had never written a post for an AIDS/HIV OHSG (totalling 84 participants, $24.7 \%$ of the sample), whereas contributors were those who had previously written at least one post. Within the study, they also developed the Empowering Processes scale which was adapted from van Uden-Kraan et al's (2008a) 29 item scale. The scale measures four distinct empowering outcomes 
associated with online health support group participation: receiving social support, finding positive meaning, receiving useful information and helping others. Findings from the study showed that lurkers were significantly less likely to agree that they had received social support and received useful information through OHSGs compared to contributors. However, there was no difference between the two groups in the extent to which they felt that they had found positive meaning and helped others. Receiving positive empowering outcomes from OHSG participation is important as they have been shown to have important ramifications for coping with illnesses. For example, Mo and Coulson (2012) demonstrated that the empowering processes of finding positive meaning and receiving useful information were associated with better adaptive coping strategies and fewer examples of maladaptive coping behaviours. In addition, the empowering processes of receiving social support and helping others were associated with improved self-care self-efficacy, which was further related to improved adaptive coping behaviour. Moreover, those individuals who opted for more maladaptive coping mechanisms reported a poorer quality of life compared to those who used more adaptive coping strategies.

Given these associations, it is therefore a matter of concern that lurkers would feel that they receive less social support and less useful information than more active participants (Mo \& Coulson, 2010) as this is likely to have important ramifications for coping behaviours and quality of life. Although Mo and Coulson (2010) suggest that support-seekers may still be able to find positive meaning from reading others' posts, it is a little harder to explain why they would feel that they had helped others equally given that they would not have replied directly to anyone on the site. One potential methodological issue with this study could be the manner in which participants were 
either classified as lurkers (if they had never made a post) or contributors (if they had made at least one post). The contributors group would have therefore contained participants covering the full spectrum of participation behaviours and other scholars have argued previously that minimal levels of posting may still be characteristic of individuals who primarily observe interactions within support communities (e.g. Ridings et al., 2006).

Further research on the empowering outcomes of lurkers and contributors in OHSGs are somewhat mixed. For example, van Uden-Kraan et al. (2008a) found that lurkers were less content with their experiences of using OHSGs and felt that they had been less empowered through the experience in terms of finding recognition for their illness and being able to exchange information with others. Petrovčič and Petrič (2014) found that contributors reported higher scores for interactional empowerment (relating to "perceptions of how...members of a group can gain psychological capacities to cope with their conditions and eventually change their disadvantaged position as a social group") than lurkers. However, there was no difference between the groups in terms of intrapersonal empowerment (relating to "individual competencies, personal control, and self-efficacy"). Tanis et al. (2011) found that users of online health forums who made more contributions experienced lower levels of caregiver strain compared to those who made fewer contributions, suggesting that more prolific posters were using the forums to gain emotional support from other members. However, van Uden-Kraan et al. (2008b) found no differences between active participators and lurkers on any empowering outcomes. 


\section{Aims of the study}

Although there is some evidence to suggest that lurkers may still receive substantial benefits from their time in OHSGs (e.g. Merry \& Simon, 2012), it has also been argued that taking the time to write about one's own experiences and supporting others by replying to their comments may lead to more substantial benefits (Ziebland \& Wyke, 2012), not just for the individual but also the online community as a whole. Although research findings on the outcomes and benefits associated with OHSG participation for lurkers and more active contributors is somewhat mixed, one problem is that many studies which have looked at this link have grouped participants into 'lurkers' and 'contributors' on the basis of whether they've previously made a contribution or not. Given the complexities in conceptualising lurking behaviour, it may be more prudent to consider degrees of participation behaviour instead. Furthermore, given the numerous different reasons for why individuals lurk within OHSGs, exploring the link between why individuals choose to lurk and the outcomes associated with this behaviour, should shed further light on helping to explain the different types of benefits that people accrue from visiting OHSGs. To this end this study aims to identify the factors which influence the propensity for individuals to engage in OHSG and to develop a scale to measure these factors. As this study is exploratory in nature no specific hypotheses have been put forward. Instead, we offer two research questions: 1) To what extent do individual reasons for lurking predict benefits or lack of benefits (e.g. empowering outcomes) that users derive from being part of an OHSG? 2) To what extent do individual reasons for lurking predict how often users post comments and reply to others? 


\section{Method}

\section{Participants}

271 participants with previous experience of accessing online health support groups participated in the study. Of these 271 participants, 34 partially completed data sets had to be removed from the analysis, leaving a final sample of 237 . The final sample included 23 men and 212 women ( 2 undisclosed) with a mean age of 25.60 (SD = .790 , range 18-100) and consisted of 140 participants from the USA, 78 from the UK, 11 from Australia and 8 participants from 5 other countries (Ireland, Spain, Norway, China and Canada). Participants indicated accessing support communities for a range of different illnesses and health conditions, but the most prevalent response was for mental health support $(n=94)$. Participants also accessed online communities for support with a variety of long term health conditions (e.g. diabetes, epilepsy and hypothyroidism), sexual health (e.g. contraception, STDs), maternal health (e.g. pregnancy, breastfeeding), nutrition and exercise, weight loss and short term illnesses (e.g. colds, flu).

\section{Materials}

\section{Propensity for Online Community Contribution Scale (POCCS)}

A new scale was developed to measure the different factors which might influence members' propensity to participate in online health support groups. Fifty-four items were developed by taking inspiration from previous research which has focused on the different reasons why people do not actively participate in online support communities (i.e. Preece et al., 2004; Sun et al., 2014). Each item on the scale required participants to indicate the extent to which they agree or disagree that the statement represents their online community participation behaviour on a 5-point 
Likert scale, ranging from strongly disagree (1) to strongly agree (5). In answering each question, participants were also asked to orient their answers to the online community that they used most regularly to access support. Participants were also given instructions to answer each question from the perspective of their behaviour in the OHSG rather than in relation to their general online behaviour. Our intention was to create a fairly comprehensive instrument which represented the most common factors which might influence propensity to participate in OHSGs.

In a pilot study, these 54 items were presented to a focus group, consisting of 3 males and 5 females, who had all previously accessed online health social support groups. The aim of the focus group was to elicit feedback on the wording of questions to ensure that they were unambiguous and easy to interpret, but also to consider how comprehensive the items were and to gather any additional suggestions for additional barriers/facilitators for participation. Questions were rephrased to address feedback, but no new items were introduced as the group felt that the primary factors influencing participation were adequately represented in the scale items.

\section{Principal Component Analysis (POCCS)}

The data for the 54 items from the 237 participants who completed the POCCS was subjected to Principal Component Analysis with Varimax rotation to ascertain a factor structure. Assumptions of sphericity $\left(X^{2}=3065.17 ; p<0.01\right)$ and sampling adequacy were met (Kaiser-Meyer-Olkin $=0.766)$. Inspection of the scree plot and Kaiser's criterion suggested a 9 factor solution. Closer inspection of the factor loadings resulted in the removal of 17 complex items which either cross-loaded on to 
two or more factors or did not load on to any other of the 9 factors. The final factor structure comprised 37 items and accounted for $58.41 \%$ of the variance, and can be seen in Table 1, including factor labels and Cronbach's alpha values. We interpreted the factors by looking for commonalities amongst items that loaded onto a single factor.

Eight of the factors describe different circumstances which might prevent people from actively contributing to online forums (factors $1,2,3,4,6,7,8$ and 9), whereas one factor ('ease of access and use') relates to a reason which might facilitate initial accessing of OHSGs. The final factors consisted of: 1) 'poor sense of community', which describes the extent to which individuals feel that they are unable to contribute because OHSGs are not cohesive or welcoming 2) 'struggles with self-expression', which describes the extent to which individuals feel that they are unable to satisfactorily articulate their messages or that their messages would not be suitably informed or interesting to other members 3) 'inhibited disclosure and privacy', which describes the extent to which concerns about privacy and disclosing too much personal information inhibits contributing to OHSGs 4) 'negative online interactions', which describes the extent to which witnessing or experiencing negative interactions with other community members might discourage future participation 5) 'ease of access and use', which describes the extent to which the intuitive and user-friendly design of the OHSG might encourage participation 6) 'health preventing contribution', which describes the extent to which a pre-existing health condition might act as a barrier to OHSG participation 7) 'delayed and selective contribution', which describes the extent to which users serve their time until they feel they are part of the community and post carefully only when they feel they have something 
accurate/relevant to say, 8) 'goals met without contribution', which describes the extent to which users can get what they need from the site without having to make a tangible contribution and 9) 'lack of time', which describes the extent to which the individual does not have sufficient time to contribute as fully as they would like to.

Table 1: Items contributing to each factor of the POCCS as well as the Cronbach's alpha scores.

\begin{tabular}{|c|c|c|c|c|c|c|c|c|}
\hline Factor & 1 & 2 & 3 & 4 & 5 & 6 & 7 & 8 \\
\hline $\begin{array}{l}\text { Factor 1: Poor sense of community } \\
\text { There is a real sense of community in the online } \\
\text { groups I visited (R). } \\
\text { Content in this community tends to be of low } \\
\text { quality. } \\
\text { I don't think you can connect with people online. } \\
\text { I don't feel that it is possible to get the emotional } \\
\text { support I need online. } \\
\text { This online community did not seem to work well } \\
\text { together. } \\
\text { This online community does not make me feel } \\
\text { welcome. }\end{array}$ & $\begin{array}{l}-.667 \\
.658 \\
.612 \\
.610 \\
.601 \\
.582\end{array}$ & & & & & & & \\
\hline $\begin{array}{l}\text { Factor 2: Struggles with self-expression } \\
\text { It is difficult to get the emotional impact of my } \\
\text { message across. } \\
\text { I feel that my thoughts would not be of interest to } \\
\text { others. } \\
\text { I find it hard to say what I mean in writing. } \\
\text { I'm concerned that I will disclose more than I } \\
\text { intended to. } \\
\text { I don't know enough about the topic to contribute. }\end{array}$ & & $\begin{array}{l}.695 \\
.610 \\
.603 \\
.593 \\
.550\end{array}$ & & & & & & \\
\hline $\begin{array}{l}\text { Factor 3: Inhibited disclosure and privacy } \\
\text { I don't want to share my problems with the rest of } \\
\text { the world. } \\
\text { I am not worried about people reading about my } \\
\text { personal problems (R). } \\
\text { I am comfortable posting to this community even if } \\
\text { I don't know the other members very well (R). } \\
\text { I felt uncomfortable posting. } \\
\text { I have concerns about privacy. } \\
\text { I feel less inhibited about sharing parts of my life } \\
\text { in an online forum (R). }\end{array}$ & & & $\begin{array}{l}.670 \\
-.657 \\
-.645 \\
.540 \\
.511 \\
-.478\end{array}$ & & & & & \\
\hline $\begin{array}{l}\text { Factor 4: Negative online interactions } \\
\text { I have posted to online communities in the past } \\
\text { but the responses to my/others post/s were } \\
\text { upsetting. } \\
\text { I've visited online communities in the past and l've }\end{array}$ & & & & $\begin{array}{l}.895 \\
.791\end{array}$ & & & & \\
\hline
\end{tabular}




\begin{tabular}{|c|c|c|c|c|c|c|c|c|c|}
\hline $\begin{array}{l}\text { witnessed others receiving abuse in response to } \\
\text { their post. } \\
\text { I/Others have posted to online communities in the } \\
\text { past but the responses to my/others' post/s were } \\
\text { unpleasant. }\end{array}$ & & & & .765 & & & & & \\
\hline $\begin{array}{l}\text { Factor 5: Ease of access and use } \\
\text { The online community is easy to access. } \\
\text { The online community is easy to use. } \\
\text { Generally online communities are very intuitive } \\
\text { and user friendly. } \\
\text { The online communities is not as active I would } \\
\text { like (R). }\end{array}$ & & & & & $\begin{array}{l}.790 \\
.720 \\
.512 \\
-.437\end{array}$ & & & & \\
\hline $\begin{array}{l}\text { Factor 6: Health preventing contribution } \\
\text { My illness sometimes gets in the way of me being } \\
\text { able to go online. } \\
\text { If my health wasn't such a problem, I would spend } \\
\text { more time in this community. } \\
\text { I feel too unwell to contribute. }\end{array}$ & & & & & & $\begin{array}{l}.833 \\
.757 \\
.743\end{array}$ & & & \\
\hline $\begin{array}{l}\text { Factor 7: Delayed and selective contribution } \\
\text { I contribute posts only when I know a lot about the } \\
\text { topic. } \\
\text { I only post when I feel that I have something } \\
\text { worthwhile to contribute. } \\
\text { I contribute posts only when I know the } \\
\text { community well. } \\
\text { I prefer to observe the way people treat each } \\
\text { other in online communities before posting myself. }\end{array}$ & & & & & & & $\begin{array}{l}.772 \\
.684 \\
.664 \\
.618\end{array}$ & & \\
\hline $\begin{array}{l}\text { Factor 8: Goals met without contribution } \\
\text { I just check posts on online communities to see if } \\
\text { I'm on the right track/doing the right things. } \\
\text { My needs were satisfied from reading others' } \\
\text { posts. } \\
\text { I use this online community solely to gather } \\
\text { information I need. } \\
\text { When visiting the online community, I feel that } \\
\text { others have typically asked the questions or made } \\
\text { the contribution I would have made. }\end{array}$ & & & & & & & & $\begin{array}{l}.711 \\
.650 \\
.557 \\
.531\end{array}$ & \\
\hline $\begin{array}{l}\text { Factor 9: Lack of time } \\
\text { I often find I am too busy to post to the online } \\
\text { community. } \\
\text { I don't have the time to post. }\end{array}$ & & & & & & & & & $\begin{array}{l}.871 \\
.667\end{array}$ \\
\hline Cronbach's alpha & .778 & .720 & .709 & .762 & .644 & .757 & .666 & .615 & .714 \\
\hline
\end{tabular}




\section{Confirmatory Factor Analysis (POCCS)}

A confirmatory factor analysis (CFA) was conducted to further examine the facture structure of the POCCS. While EFA is designed to locate patterns in the data without a priori stipulations, CFA uses a pre-determined factor model. Specifically, CFA tests the correlational structure of a data set against the model's implied structure and evaluates the "goodness of fit" (Mvududu \& Sink, 2005). A general rule of thumb for a good model fit is RMSEA and SRMR $\leq .08$; and CFI $\geq .90$ (McDonald \& Ho, 2002). Results of the CFA indicated moderate to good model fit, $X^{2}=1134.08$ $(p<.001), \mathrm{RMSEA}=.06,90 \% \mathrm{Cl}[.05-.06], \mathrm{CFI}=.80, \mathrm{SRMR}=.08$. Table 2 summarizes the fit indices for the 9 factor model. Inspection of individual path coefficients indicated that all items significantly loaded on corresponding factors $(p<$ .01 for all loadings; see figure 1). Overall, these results support the hypothesized structure of the scale and provide evidence for its factorial validity.

Table 2: Summary of Fit Indices for POCCS

\begin{tabular}{|l|l|l|l|l|l|l|l|}
\hline Model & $x^{2}$ & $\mathrm{df}$ & $p$ value & CFI & TLI & SRMR & RMSEA \\
\hline 9 factor & 1134.08 & 594 & $p<0.01$ & 0.797 & 0.772 & 0.075 & 0.059 \\
\hline
\end{tabular}


Figure 1: Path coefficients for the nine factors of the POCCS

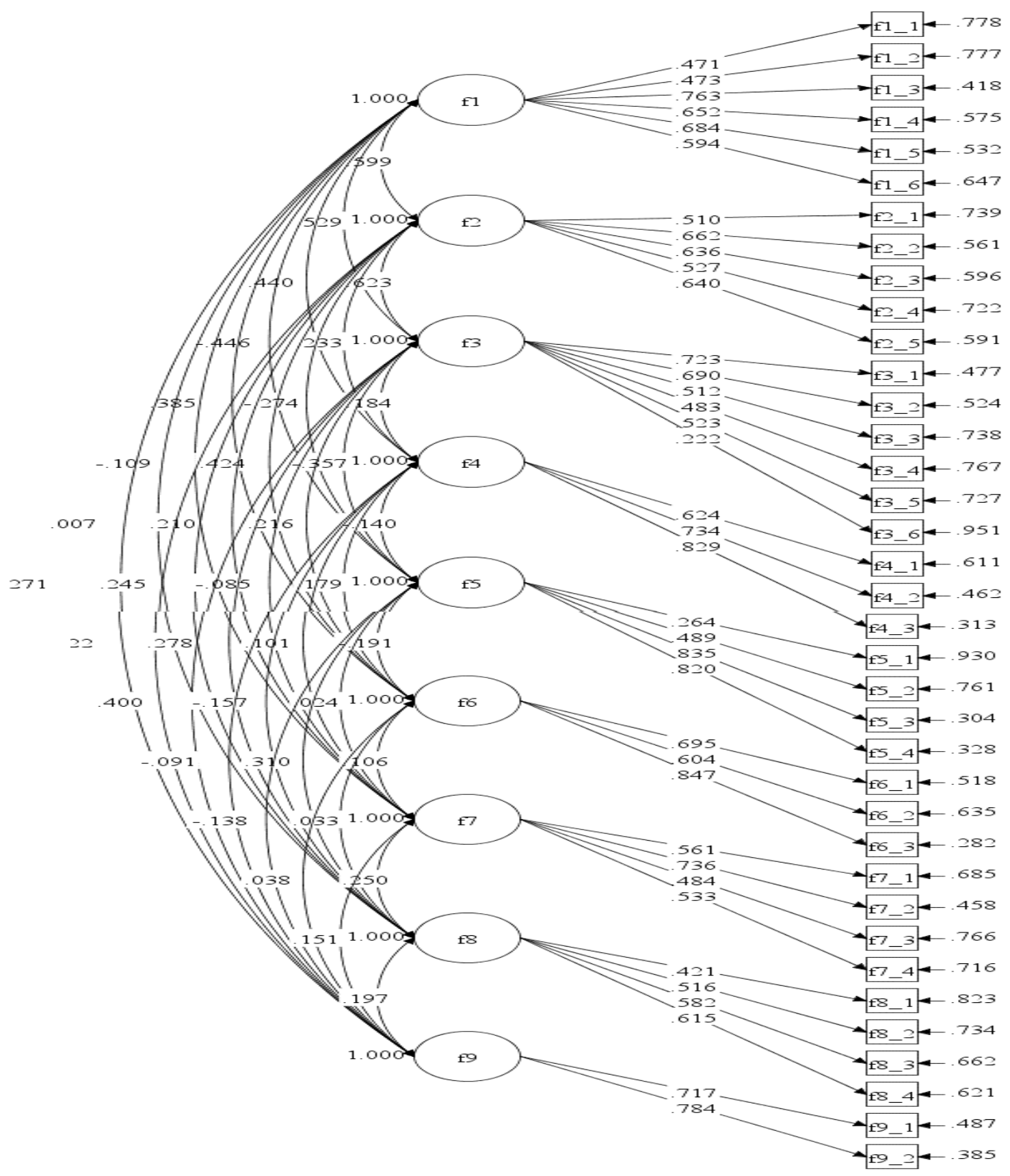

\section{Empowering Processes scale}

The Empowering Processes scale (Mo \& Coulson, 2010) is a 39 item scale which measures the different empowering effects and benefits associated with participating in online support groups. Items are rated on a 5-point Likert scale ranging from 1 (never) to 5 (often). The scale includes four sub-scales of 'receiving social support', 
'finding positive meaning', 'receiving useful information' and 'helping others'. The sub-scales have good to excellent reliability with Cronbach's alpha values of .94 for receiving social support, .95 for finding positive meaning, .91 for receiving useful information and .87 for helping others. Sample questions for each of the sub-scales include: 'someone in the group consoles you' (receiving social support); 'someone/message in the group helps you find new and worthwhile goals' (finding positive meaning); 'information exchanged is valuable' (receiving useful information) and 'you can share your everyday experiences with others' (helping others).

Additional questions were also included in the survey which requested information from participants in relation to which communities they visited, which support needs they were trying to meet, their online support group behaviour (i.e. how regularly they constructed original posts and how often they replied to others' posts) and perceptions of outcomes associated with engagement (i.e. whether their specific needs had been met by visiting the OHSG).

\section{Procedure}

Active recruitment took place in the UK, USA, Ireland, and Australia via several means. First, each researcher advertised the study on the participant pool of their host institution. Second, emails were sent out to moderators of various online support groups for people with mental health concerns and chronic physical health conditions such diabetes and MS, carers, and expectant parents. Where permission had been granted, an advertisement to the study was placed on the site. Third, each of the authors promoted the study via their personal social media profiles. Finally, the study was advertised on the UK researchers' research group webpage. In each 
case, participants were given the option to nominate themselves to be placed into a draw to win one of eight gift vouchers (of $\$ 20 A U D, \$ 20$ USD or $£ 20$, whichever was their local currency). Participants were provided with a link to an online survey hosted by www.Psychdata.com. Both information and consent were provided to participants on-screen. This included information on withdrawing their data from the study, confidentiality and anonymity. After completing the fixed order survey, participants were provided with debriefing information and contact details for the lead researcher should they have any questions. At this point, participants were able to provide their email address should they wish to be included in the prize draw.

\section{Results}

\section{Propensity for Online Community Contribution Scale correlations}

Each of the 9 factors of the POCCS were correlated with each other (Spearman's rho). The correlational and descriptive statistics are shown in Table 3 below.

Table 3: Descriptive statistics (standard deviations in brackets) and intercorrelations for each of the 9 POCCS factors

\begin{tabular}{|l|l|l|l|l|l|l|l|l|l|l|}
\hline & $\begin{array}{l}\text { Mean } \\
(\mathrm{SD})\end{array}$ & $(1)$ & $(2)$ & $(3)$ & $(4)$ & $(5)$ & $(6)$ & $(7)$ & $(8)$ & $(9)$ \\
\hline $\begin{array}{l}2.38 \\
(1) \text { Community }\end{array}$ & 1.00 & & & & & & & & \\
\hline & $\begin{array}{l}\text { (2) Self-expression } \\
(.772)\end{array}$ & $.441^{\star \star}$ & 1.00 & & & & & & & \\
\hline (3) Disclosure/Privacy & $\begin{array}{l}3.08 \\
(.685)\end{array}$ & $.386^{\star \star}$ & $.377^{\star \star}$ & 1.00 & & & & & & \\
\hline $\begin{array}{l}\text { (4) Negative interactions } \\
2.63 \\
(.896)\end{array}$ & $.269^{\star \star}$ & $.134^{\star}$ & $.139^{\star}$ & 1.00 & & & & & \\
\hline $\begin{array}{l}\text { (5) Ease of access \& } \\
\text { use }\end{array}$ & $\begin{array}{l}3.79 \\
(.495)\end{array}$ & $-.427^{\star \star}$ & $-.185^{\star \star}$ & $-.272^{\star \star}$ & $-.164^{\star \star}$ & 1.00 & & & & \\
\hline $\begin{array}{l}\text { (6) Health } \\
2.26 \\
(.828)\end{array}$ & $.262^{\star \star}$ & $.314^{\star \star}$ & $.123^{\star}$ & .109 & $-.196^{\star \star}$ & 1.00 & & & \\
\hline $\begin{array}{l}\text { (7) Selective } \\
\text { contribution }\end{array}$ & $\begin{array}{l}3.47 \\
(.652)\end{array}$ & -.072 & .105 & -.005 & .080 & .064 & .095 & 1.00 & & \\
\hline (8) Goals met & $\begin{array}{l}3.66 \\
(.609)\end{array}$ & .029 & $.202^{\star \star}$ & $.211^{\star \star}$ & -.095 & $.191^{\star \star}$ & .054 & $.163^{\star \star}$ & 1.00 & \\
\hline (9) Lack of time & $\begin{array}{l}3.24 \\
(.924)\end{array}$ & $.223^{\star \star}$ & $.322^{\star \star}$ & $.275^{\star \star}$ & -.075 & -.058 & .045 & $.132^{\star}$ & $.157^{\star}$ & 1.00 \\
\hline
\end{tabular}

$$
{ }^{*} \mathrm{p}<0.05,{ }^{* *} \mathrm{p}<0.01
$$


Of particular note is that 'ease of access and use' correlated significantly and negatively with all of the POCCS factors, except 'lack of time' and 'selective contribution', which both did not correlate with 'ease of access and use'. This suggests that having an intuitive and user-friendly system might encourage selfexpression and disclosure and may also promote a better sense of community.

\section{Propensity for Online Community Contribution factors and OHSG contribution} behaviour

To test whether barriers to OHSG participation are associated with the types and frequencies of contributions people make, the nine factors of the POCCS were entered as predictors into two separate linear regressions (enter method) with 'construct original post frequency' and 'replying to others frequency' as the dependent variables in each respective regression. Both of DVs were measured on a 5 point Likert scale ranging from 'never' (1) to 'very often' (5).

\section{Construct original post frequency}

Predictors explained $28.4 \%$ of the variance (adjusted $\mathrm{R}^{2}=.256$ ) in 'construct original post frequency' $(F(9,227)=10.01, p<.01)$. Of the predictors, 'poor sense of community' (beta $=-.219, t=-3.06, p<0.01$, ) 'inhibited disclosure and privacy' (beta $=$ -.257, $t=-3.93, p<0.01$ ), 'health preventing contribution' (beta $=.214, t=3.56$, $p<0.01$ ) and 'goals met with contribution' (beta $=-.266, t=-4.28, p<0.01$ ) made significant independent contributions to the explained variance. Thus, those who were inhibited from making contributions to OHSGs because a) they felt that there was a poor sense of community, b) had concerns about privacy and disclosure, or c) 
their goals were met without making an active contribution, were less likely to construct an original post. However, those who thought that their health impacted on their ability to make a contribution were more likely to construct an original post.

\section{Replying to others frequency}

Predictors explained $29.7 \%$ of the variance (adjusted $R^{2}=.269$ ) in 'replying to others frequency' $(F(9,225)=10.56, p<.01)$. Of the predictors, 'poor sense of community' (beta $=-.235, t=-3.27, p<0.01$ ) 'inhibited disclosure and privacy' (beta $=-.162, t=-$ 2.47, $p<0.05$ ), 'negative online interactions' (beta $=.150, t=2.50, p<0.05$ ) and 'goals met without contribution' (beta $=-.283, t=-4.63, p<0.01$ ) made significant independent contributions to the explained variance. Thus, those who were inhibited from making contributions to OHSGs because a) they felt that there was a poor sense of community, b) had concerns about privacy and disclosure, or c) their goals were met without making an active contribution, were less likely to reply to others. However, those who reported witnessing or experiencing negative interactions in OHSGs were more likely to reply to others.

Propensity for Online Community Contribution Scale factors and positive experiences of OHSG engagement

To test whether the factors influencing online support group participation are associated with the types of benefits and positive experiences that people accrue from OHSG engagement, the 9 POCCS factors were entered as predictors into 5 separate linear regressions (enter method) with 'needs met through participation' and the 4 Empowering Processes factors of "receiving social support', 'finding positive meaning', 'receiving useful information' and 'helping others' as the 
dependent variables in each respective regression. 'Needs met through participation' was measured on a 5 point Likert scale ranging from 'never' (1) to 'always' (5). Each of the 4 Empowering Processes sub-scales were measured on a 5 point Likert scale ranging from 'never' (1) to 'often' (5).

\section{Needs met through participation}

Predictors explained $18.7 \%$ of the variance (adjusted $\mathrm{R}^{2}=.158$ ) in whether needs had been met through participation $(F(9,227)=6.33, p<.01)$. Of the predictors, 'poor sense of community' (beta $=-.413, t=-5.61, p<0.01$ ) and 'inhibited disclosure and privacy' (beta $=-.138, t=-2.04, p<0.05)$ made significant independent contributions to the explained variance. Thus, those who were inhibited from making contributions to OHSGs because a) they felt that there was a poor sense of community and b) had concerns about privacy and disclosure, were less likely to feel that their needs had been met through participation in OHSGs.

\section{Receiving social support}

Predictors explained $35.2 \%$ of the variance (adjusted $\mathrm{R}^{2}=.327$ ) in the 'receiving social support' factor of the Empowering Processes scale $(F(9,229)=13.84, p<.01)$. Of the predictors, 'poor sense of community' (beta $=-.400, t=-5.88, p<0.01$ ) 'inhibited disclosure and privacy' (beta $=-.252, t=-4.00, p<0.01$ ), 'health preventing contribution' (beta $=.281, t=4.86, p<0.01$ ) and 'selective contribution' (beta $=.143$, $t=2.56, p<0.05)$ made significant independent contributions to the explained variance. Thus, those who were inhibited from making contributions to OHSGs because a) they felt that there was a poor sense of community and b) had concerns about privacy and disclosure, were less likely to feel that they had received social 
support. However, those who a) thought that their health impacted on their ability to make a contribution, and b) those who 'selectively' contributed were more likely to feel that they had received social support.

\section{Finding positive meaning}

Predictors explained $24.9 \%$ of the variance (adjusted $\mathrm{R}^{2}=.220$ ) in the 'finding positive meaning' factor of the Empowering Processes scale $(F(9,229)=8.45$, $p<.01$ ). Of the predictors, 'poor sense of community' (beta $=-.367, t=-5.02, p<0.01$ ) 'inhibited disclosure and privacy' (beta $=-.185, t=-2.74, p<0.01$ ), and 'health preventing contribution' (beta $=.169, t=2.71, p<0.01$ ) made significant independent contributions to the explained variance. Thus, those who were inhibited from making contributions to OHSGs because a) they felt that there was a poor sense of community and b) had concerns about privacy and disclosure, were less likely to feel that they had found positive meaning from the OHSGs they had visited. However, those who thought that their health impacted on their ability to make a contribution were more likely to feel that they had found positive meaning.

\section{Receiving useful information}

Predictors explained $28.1 \%$ of the variance (adjusted $R^{2}=.253$ ) in the 'receiving useful information' factor of the Empowering Processes scale $(F(9,229)=9.97$, $p<.01$ ). Of the predictors, only 'poor sense of community' (beta $=-.371, t=-5.18$, $p<0.01$ ) made a significant independent contribution to the explained variance. Thus, those who were inhibited from making contributions to OHSGs because they felt that there was a poor sense of community were less likely to feel that they had found received useful information from the OHSGs they had visited. 


\section{Helping others}

Predictors explained $30.4 \%$ of the variance (adjusted $R^{2}=.276$ ) in the 'helping others' factor of the Empowering Processes scale $(F(9,228)=11.05, p<.01)$. Of the predictors, 'poor sense of community' (beta $=-.298, t=-4.23, p<0.01$ ) 'inhibited disclosure and privacy' (beta $=-.264, t=-4.06, p<0.01$ ), 'health preventing contribution' (beta $=.164, t=2.73, p<0.01)$, 'selective contribution' (beta $=.182, t=$ $3.12, p<0.01$ ) and 'goals met with contribution' (beta $=-.133, t=-2.17, p<0.05$ ) made significant independent contributions to the explained variance. Thus, those who were inhibited from making contributions to OHSGs because a) they felt that there was a poor sense of community, b) had concerns about privacy and disclosure and c) whose goals were met without contributing were less likely to feel that they had helped others in the OHSGs they had visited. However, those who a) thought that their health impacted on their ability to make a contribution, and b) those who 'selectively' contributed were more likely to feel that they had helped others.

\section{Summary}

Poor sense of community affected making fewer original posts, replying to fewer people, receiving less social support, finding less meaning, receiving less useful information, helping fewer others and perceptions that needs were less likely to be met. Inhibited disclosure and privacy predicted making fewer original posts, replying to fewer people, receiving less social support, finding less meaning, helping fewer others and perceptions that needs were less likely to be met. Health preventing contribution affected making more original posts, receiving more social support, finding more meaning and helping more others. Goals met without contribution lead 
to making fewer original posts, replying to fewer people and helping fewer others. Selective contribution predicted receiving more social support and helping more others. Negative online interactions affected replying to more others. Struggles with self-expression, ease of access and use and lack of time did not contribute significantly to any of the regression models.

\section{Discussion}

This study extends current understanding about lurking behaviours in OHSGs by exploring factors that affect participants' propensity for contributing to online health support groups and how these predict the frequency with which posts/replies are made and the perceived outcomes of visiting these communities. Nine explanations for individuals' propensity to contribute to OHSGs were identified: 1) poor sense of community; 2) struggles with self-expression; 3) inhibited disclosure and privacy; 4) negative online interactions; 5) ease of access and use; 6) health preventing contribution; 7) delayed and selective contribution; 8) goals met without contribution; and 9) lack of time. Five of these reasons (factors 1, 3, 6, 7, and 8) significantly predicted participants' frequency of OHSG interactions, and the types of benefits derived from visiting online communities. Negative online interactions positively predicted frequency of replying to others, while struggles with self-expression, ease of access, use and lack of time were not significant predictors of OHSG participation or perceived benefits of visiting OHSGs.

The variety of reasons for different levels of participation in OHSGs suggests that conceiving of, and operationalising, lurking as a dichotomous variable (i.e. people post or they do not) may be oversimplifying the construct and limiting research in the field. Despite many studies reporting negative outcomes for lurkers (Mo \& Coulson, 
2010; Tanis, Das \& Fortgens-Sillman, 2011; Tobin, Vanman, Verreynne \& Saeri, 2015), others have also found that lurkers do perceive a sense of belonging and report satisfaction with their online community experiences (Merry \& Simon 2012). The current findings suggest that reasons for lurking behaviour may explain these discrepant findings. For example, someone interested in diet options for Type II diabetes might enter an online community and find that their question has already been asked and answered. In this situation, the person is able to achieve their goals and may report a positive outcome from the visit despite not posting a contribution. Thus, by understanding the reasons for non-active participation in OHSGs, we can provide more nuanced understanding of the relationship between OHSG use and perceived outcomes.

\section{Poor sense of community and inhibited disclosure}

Our study explored this further by investigating the relationships between factors that prevented OHSGs use and the degree to which participants felt that visiting OHSGs met their needs and enabled them to receive social support, find positive meaning in their experiences, receive useful information, and help others. When lurking behaviours were motivated by a poor sense of community on the OHSG or feeling inhibited or uncomfortable disclosing, participants contributed original posts and replies less frequently, and were less likely to feel that they had their needs met,

received social support, found positive meaning, and helped others (poor sense of community was also related to feeling that useful information was not received through the OHSGs). This suggests, and is consistent with previous research showing, that an inclusive culture is important for deriving positive outcomes among lurkers of OHSGs (Sun, et al., 2014). 
That ease of access of use was not related to frequency of posts or empowerment processes further highlights the value of the interactions in OHSGs. Making OHSGs technically accessible may therefore be a necessary but not a sufficient condition for facilitating positive outcomes associated with visiting OHSGs. That is, ease of accessing the online community may be important for exposure to the potential support, but it is the nature of the interactions in the community that actually bestows the benefits of empowerment processes rather than the ease of use of the technology. In contrast, the aspects of technology that do impact positive outcomes directly promote or facilitate self-disclosure and communication; these include asynchronicity and anonymity (Barak et al., 2008).

\section{Health preventing contribution}

Participants who believed their health condition limited their capacity to contribute to online discussions reported posting original messages more often, and feeling that they had received social support, found positive meaning, and helped others. It may be that the health condition limits the opportunities an individual has to access the online community so when they are able to, they will post about what is most immediately relevant to them, for instance a question or recent experience. In doing so, they receive social support from their peers, but may also provide vicarious support for others who have experienced similar circumstances and may feel that the original post resonates with their personal circumstances. Mo and Coulson (2014) found that emotional support can motivate OHSG posting as it can alleviate some of the burden of the experience. If opportunities to engage with an online community 
are limited, an individual may choose to construct a new post (rather than a reply) so as to derive this social support.

Posting messages in OHSGs requires individuals to organise their thoughts and articulate their concerns. Research has shown that constructing and co-constructing a narrative around an individual's health experiences can help them make sense of their experiences and facilitate the healing process (Ziebland \& Wyke, 2012). In addition to the benefits to the individual, numerous studies also report that OHSG users are encouraged by the belief that in sharing their stories and questions, they are able to help others experiencing similar concerns (Buchanan \& Coulson, 2007; van Uden-Kraan et al., 2008a, Mo \& Coulson, 2014). It is possible, then, that even if someone posts intermittently about themselves they believe they are also helping others. Although these explanations are supported by the literature, the crosssectional nature of this study limits the strength of the conclusions that can be drawn. Future research should consider a more longitudinal or ethnographic approach where the experiences of people with chronic conditions in OHSGs can be explored in greater depth over time.

\section{Goals met}

When participants did not actively contribute to OHSGs because their goals for going online had been met, they contributed new posts and replied to others less often, and felt that they had helped others less frequently. Further research could be conducted to investigate the types of goals that are met without active contributions. It is hypothesised that these goals are information-based (i.e. an individual searching for a direct answer to a simple question). In this way, the individual's visit to an 
OHSG is unlikely to be related to receiving support or finding positive meaning. The information provided in online communities can vary in quality (Mo \& Coulson, 2014) which may explain the non-significant relationship between lurking behaviour because goals have been met and finding useful information in OHSGs.

\section{Negative online interactions}

The results also showed that individuals who were less motivated to actively participate because they had previous exposure to negative interactions on OHSGs, more frequently replied to posts than individuals who had experienced fewer previous negative interactions. One potential explanation is that responses to threaded conversations are less visible (or exposed) than new original posts. Having seen negative exchanges in online communities previously, when the person wants to contribute, they may be reluctant to put themselves in a position where they are more exposed to scrutiny. On the other hand, replies might allow users to defend ideas and peers against negative feedback and to provide more supportive messages in response to seeing so many negative posts. Whilst these ideas require further investigation, of note is the importance of the types of interactions rather than the frequency of interactions. The emotional valence or tone of messages may be better predictors of others' responses and future behaviours than the number of messages someone posts or is exposed to. Again, further research is needed here.

\section{Limitations and future directions}

This study provides further evidence for the breadth of reasons for why individuals might refrain from active participation in online communities. These reasons impact how people engage with, and on, OHSGs and what benefits they derive from these 
interactions. An ethnographic approach where researchers are immersed in the online community and its users over time would enable more in-depth exploration of the relationship between motivation, OHSG use, and empowerment outcomes. The cross-sectional, quantitative approach used in this study lacks the time ordering aspect required to discern causative relationships and hence limits the types of conclusions that can be drawn.

To obtain an overview of the factors affecting, and affected by, lurking behaviours in online health support groups, this study was inclusive in its definition of health OHSGs. For example, the temporary experiences of pregnancy differ from experiences of people with chronic or terminal and chronic conditions in terms of duration and potential stigma. It is also worth acknowledging that the sample primarily consisted of females, and two countries (USA and UK) were most heavily represented. Future research could focus on particular types of health conditions and, with greater sample sizes (including more male participants), compare the pattern of relationships across the different contexts and cultures. This study used a self-report measure that focussed on participants' perceptions. Future studies could compare both the perceptions of interactions and actual messages exchanged in online communities. Factors that might affect this include participants' expectations of OHSGs and their specific needs. Furthermore, given the preliminary nature of this work, future research using the POCCS should focus on further testing of the psychometric properties not addressed in this initial study. One other potential limitation is that the POCCS includes statements about experiences within specific OHSGs, and statements that reflect participants' engagement with, and attitudes towards, OHSGs more broadly. Despite explicit instructions to participants to focus 
on a particular OHSG, there may be some confounding between specific experiences and beliefs about OHSGs more broadly. It is worth noting, though, that the POCCS aims to measure motivations for lurking, and a person's decision to lurk within a particular community is a result of both their experiences with this specific OHSG and OHSGs generally. The EFA and CFA confirm the structure of the POCCS even with this potential limitation.

Future research into motivations for using (or lurking on) online communities, the types of interactions that occur in, and the well-being outcomes that are derived from OHSGs could also be used to inform the design and use of online communities. Knowing that poor sense of community and inhibited self-disclosure are factors that reduce posting and perceived benefits of OHSG use, online communities could be strategically designed to address these issues. Fullwood (2016) describes strategies for creating a sense of community (e.g., encouraging people to contribute early in the cycle and to offer support as well as seek it, provide support for, and welcome, new members) and promoting contributions (e.g. using anonymous groups where appropriate, creating an inclusive culture where all contributions are valued, and making the privacy settings and policies explicit). In addition to factors promoting community and disclosure, future research could also investigate whether the extent to which the design of an online community considers its users' needs is related to the culture of the group, and thereby the positive outcomes derived from exposure to this group. 


\section{Conclusions}

Despite ongoing discussion about defining lurking, research investigating online lurking behaviours has traditionally operationalised it as a dichotomous variable - has an individual posted or not? The nine POCCS factors identified in this study highlight the need to consider a more nuanced approach to studying people's propensity to contribute, or not, to online forums. This enables the research to be more inclusive and moves away from a potentially oversimplified understanding of lurking behaviour. In addition, the variety of reasons for lurking behaviour has been shown to differentially predict frequency of posting new contributions, or replies to existing posts on OHSGs. Different reasons for lurking behaviour also predict the type of benefits people derive from visiting online communities and the extent to which these benefits are perceived. Future research could usefully extend this work towards further disentangling the potential reasons for the relationships between specific reasons for lurking and the empowerment processes the user engages in. Such studies are required across a range of health conditions and OHSG.

\section{Acknowledgements}

We would like to thank Paul Yeats, Center for Research Design \& Analysis at Texas Woman's University, for his assistance with the confirmatory factor analysis. 


\section{References}

Barak, A., Boniel-Nissim, M., \& Suler, J. (2008). Fostering empowerment in online support groups. Computers in Human Behavior, 24(5), 1867-1883.

Broadhead, W.E., Kaplan, B.H., James, S.A., Wagner, E.H., Schoenbach, V.J., Grimson, R., Heyden, S., Tibblin, G., \& Gehlbach, S.H. (1983). The epidemiologic evidence for a relationship between social support and health. American Journal of Epidemiology, 117, 521-537.

Buchanan, H., \& Coulson, N. S. (2007). Accessing dental anxiety online support groups: An exploratory qualitative study of motives and experiences. Patient Education and Counseling, 66(3), 263-269.

Caplan, S. E., Turner, J. S. (2007). Bringing theory to research on computermediated comforting communication. Computers in Human Behavior, 23, 985-998.

Cutrona, C., \& Russell, D. (1990). Type of social support and specific stress: Toward a theory of optimal matching. In B. Sarason, I. Sarason \& G. Pierce (Eds.), Social support: An interactional perspective (pp. 319-366). New York: Wiley.

Coker, A.L., Smith, P.H., Thompson, M.P., McKeown, R.E., Bethea, L., \& Davis, K.E. (2002). Social support protects against the negative effects of partner violence on mental health. Journal of Women's Health and Gender-Based Medicine, 11(5), 465476.

Coulson, N., \& Smedley, R. (2015). A focus on online support. In A.Attrill (Ed.), Cyberpsychology (pp.197-213). Oxford: Oxford University Press.

Edelmann, N. (2013). Reviewing the definitions of 'lurkers' and some implications for online

research. Cyberpsychology, Behavior \& Social Networking, 16(9), 645-649.

Eysenbach, G., Powell, J., Englesakis, M., Rizo, C., \& Stern, A. (2004). Health related virtual communities and electronic support groups: systematic review of the effects of online peer to peer interactions. British Medical Journal, 328(7449), 1166. Fullwood, C. (2016). Online support groups: Enhancing the user experience with cyberpsychological theory. In A. Attrill \& C. Fullwood (Eds.). Applied Cyberpsychology: Practical applications of cyberpsychological research and theory. Palgrave Macmillan.

Lup, K., Trub, L., \& Rosenthal, L. (2015). Instagram\# instasad?: exploring associations among instagram use, depressive symptoms, negative social 
comparison, and strangers followed. Cyberpsychology, Behavior, and Social Networking, 18(5), 247-252.

Malinen, S. (2015). Understanding user participation in online communities: A systematic literature review of empirical studies. Computers in human behavior, 46, 228-238.

Mason, B. (1999). Issues in virtual ethnography. Paper presented at the Ethnographic studies in real and virtual environments: inhabited information spaces and connected communities conference, Edinburgh.

McDonald, R. P., \& Ho, M. H. R. (2002). Principles and practice in reporting structural equation analyses. Psychological methods, 7(1), 64.

McKenna, K., \& Bargh, J. (1998). Coming out in the age of the Internet:

"Demarginalization" through virtual group participation. Journal of Personality and Social Psychology, 75, 681-694.

Merry, S.K., \& Simon, A. (2012). Living and lurking on LiveJournal: The benefits of active and non-active membership. Aslib Journal of Information Management, 64, 241-261.

Mickelson, K. D. (1997). Seeking social support: Parents in electronic support groups. In S. Kiesler (Ed.), Culture of the Internet (pp. 157-178). Mahwah, NJ: Erlbaum.

Mo, P.K.H., \& Coulson, N.S. (2010). Empowering processes in online support groups among people living with HIVIAIDS: A comparative analysis of 'lurkers' and 'posters'. Computers in Human Behavior, 26(5), 1183-1193.

Mo, P. K., \& Coulson, N. S. (2012). Developing a model for online support group use, empowering processes and psychosocial outcomes for individuals living with HIVIAIDS. Psychology \& Health, 27(4), 445-459.

Mo, P.K.H., \& Coulson, N.S. (2010). Are online support groups always beneficial? A qualitative exploration of the empowering and disempowering processes of participation within HIVIAIDS-related online support groups. International Journal of Nursing Studies, 51, 983-993.

Muller, M. (2012). Lurking as a personal trait or situational disposition? Lurking and contributing in enterprise social media. CSCW '12 Proceedings of the ACM 2012 conference on Computer Supported Cooperative Work, Seattle, Washington, USA. February $11-15$. 
Mvududu, N. H., \& Sink, C. A. (2013). Factor analysis in counseling research and practice. Counseling Outcome Research and Evaluation, 4(2), 75-98.

Nonnecke, B. (2000). Lurking in email-based discussion lists. Unpublished PhD dissertation, South Bank University, London.

Nonnecke, B., \& Preece, J. (2000). Lurker demographics: counting the silent. Paper presented at the ACM CHI 2000 conference on human factors in computing systems, The Hague.

Nonnecke, B., \& Preece, J. (2001). Why lurkers lurk. AMCIS 2001 Proceedings, 294. Nonnecke, B., \& Preece, J. (2003). Silent participants: Getting to know lurkers better. From

Usenet to CoWebs: Interacting with social information spaces, 110-132.

Nonnecke, B., Preece, J. J., Andrews, D., \& Voutour, R. (2004, August). Online lurkers tell why. In Paper presented at the Tenth Americas Conference on Information

Systems. New York.

Petrovčič, A., \& Petrič, G. (2014). Differences in intrapersonal and interactional empowerment between lurkers and posters in health-related online support communities. Computers in Human Behavior, 34, 39-48.

Petrovčič, A., Petrič, G., \& Manfreda, K. L. (2016). The effect of email invitation elements on response rate in a web survey within an online community. Computers in Human Behavior, 56, 320-329.

Preece, J., Nonnecke, B., \& Andrews, D. (2004). The top five reasons for lurking: Improving community experiences for everyone. Computers in Human Behavior, 20, 201-223.

Ridings, C., Gefen, D., \& Arinze, B. (2006). Psychological barriers: Lurker and poster motivation and behavior in online communities. Communications of the Association for Information Systems, 18(1), 16.

Seigfried-Spellar, K. C., \& Lankford, C. M. (2018). Personality and online environment factors differ for posters, trolls, lurkers, and confessors on Yik Yak. Personality and Individual Differences, 124, 54-56.

Sun, N., Rau, P. P. L., \& Ma, L. (2014). Understanding lurkers in online communities: A literature review. Computers in Human Behavior, 38, 110-117.

Tanis, M., Das, E., \& Fortgens-Sillman, M. (2011). Finding care for the caregiver? Active participation in online health forums attenuates the negative effect of 
caregiver strain on wellbeing. Communications: The European Journal of Communication Research, 36, 51-66.

Taylor, J., \& Turner, J. (2001). A longitudinal study of the role and significance of mattering to others for depressive symptoms. Journal of Health and Social Behavior, 42, 310-325.

Tobin, S., Vanman, E., Verreynne, M., \& Saeri, A. (2015). Threats to belonging on Facebook: lurking and ostracism. Social Influence, 10, 31-42.

Valkenburg, P. M., Schouten, A. P., \& Peter, J. (2005). Adolescents' identity experiments on the Internet. New media \& society, 7(3), 383-402.

van Uden-Kraan, C. F., Drossaert, C. H. C., Taal, E., Seydel, E. R., \& van de Laar, M. A. F. J. (2008a). Self-reported differences in empowerment between lurkers and posters in online patient support groups. Journal of Medical Internet Research, 10(2), e18.

van Uden-Kraan, C. F., Drossaert, C. H. C., Taal, E., Shaw, B. R., Seydel, E. R., \& van de Laar, M. A. F. J. (2008b). Empowering processes and outcomes of participation in online support groups for patients with breast cancer, arthritis, or fibromyalgia. [Research Support, Non-US Gov't]. Qualitative Health Research, 18(3), 405-417.

White, M., \& Dorman, S.M. (2001). Receiving social support online: Implications for health education. Health Education Research: Theory and Practice, 16(6), 693-707. Whitty, M. T., \& Joinson, A. (2008). Truth, lies and trust on the Internet. Routledge. Ziebland, S., \& Wyke, S. (2012). Health and illness in a connected world: How might sharing experiences on the Internet affect people's health? The Milbank Quarterly: A Multidisciplinary Journal of Population Health and Health Policy, 90, 219-249. 